\title{
Milk quality testing using intelligent inference performance evaluation system integrated with IoT
}

\author{
G. Suresh Babu *, V. Rama Krishna, V. Dharma Teja, S. Balraj Yadav \\ Computer Science \& Engineering Department, (KLEF) KL University, Vaddeswaram, Andhra Pradesh. \\ *Corresponding author E-mail:Surya2krishna95@gmail.com
}

\begin{abstract}
One of the major used food item in day to day life is milk. Many large-scale industries are in the distribution of milk products. Quality of milk is one of the major factor in the food processing system and customers appreciate quality products. IoT is revolution and it is using extensively in our day to day life. Our project is about maintaining the quality of the milk as it's a perishable product. In this paper we concentrated on how the milk is depending on the different factors available in it and each one effects the quality. An attempt is made to analyze the data from the sensors with IoT used in the milk production with the help of Artificial Neural Network (ANN). The results are exhibited through an example.
\end{abstract}

Keywords: ANN, FTIR, SNF, random forest, neural net.

\section{Introduction}

Now a days, the food transport and their safety is taking a major role in the remote locations as well as developed locations. Many literature reviews are widely discussing on quality and safety [1], [2]. Many research areas are discussing the temperature levels as temperature takes a main role in changes in food quality. Jun et al. [3] proposed theoretical approach to analyse the quality of aquatic products in different types of temperature fluctuations. If we take a part of food supply, we can see lots of areas where vast amount of food supply is going on. In the category of food, we can consider fruits, milk, raw materials, etc. In this process of transport and serving of food, preserving the food quality is one of the major issues. If we consider about raw material food items, we can sense their quality on the run time as those will be kept in a box and those items can be surrounded by sensors (IoT devices) to test their smell, colour, and the presence of some gases present in that box, but if we consider about the milk we can't keep it exposed to open environment as its mixes with lots of minerals and chemicals available in the air that can quickly damage the quality of milk. But as the technology is evolving rapidly, the technology in the field of IoT has also developed greatly. Earlier we had to use 3-4 sensors (IoT devices $[4,5]$ ) to test the quality of some limited factors. But now we have full technical equipment to test all factors available in milk. Generally, milk distribution is a very widespread business as it is commonly available all around the world. As a part of taking care of milk quality we have given a detailed explanation of the quality factors and the quality tests. We mentioned about milk in this paper in detail to be useful to the manufacturers as well as the consumers in maintaining the milk quality. From an experimental process what we know about milk is that it will not get damaged but the factors present in the milk change continuously which causes bad smell to emerge from milk. By this analysis we conclude that the milk can be used even though it has a bad smell. Moreover, it doesn't cause any harm to health. The milk preservation method is also very easy-boil the milk normally to make it last for one day. If we want to keep it for another day we repeat the same process (boil it and store it). This process will keep the milk fresh for 24 hours and this process can be repeated for maximum 2 times. Beyond this the milk will start degrading and will finally start rotting. This paper explains the factors we calculate in the milk and what will effect in milk quality and how those factors will effect on the milk. The presentation comprises of about technology related to milk quality can be assessed is given in section I, about technology related to milk quality has been studied given in section II. A numerical example has been presented in the section III and Experimental results are discussed in section IV.

\section{Related work}

In this paper the quality of the milk is analyzed by using Artificial Neural Network. Artificial Neural Network works similarly as the function of the brain's neurons. A group of connected units or nodes called artificial neurons are present in ANN [6]. Each connection present between artificial neurons sends a signal from one to another. In ANN implementations [7], the signal at a connection between artificial neurons generates a real number, and the output of each artificial neuron is calculated by a non-linear function of the sum of its inputs. We have taken eight different factors which emerges during the testing of the milk and by using their values we find a SNF value and based on that value we can justify whether the tested sample of milk is of good quality or not. These factors are used in constructing the ANN and are used in getting SNF values. The eight factors used in the project to construct ANN are C.O.B, ACIDITY, HEAT STABILITY, MBRT, PHOSPHATE, ALCOHOL, FAT and CLR. The following is a table that describes these factors in testing of milk: 


\begin{tabular}{|c|c|c|c|}
\hline $\begin{array}{l}\text { Serial } \\
\text { no }\end{array}$ & Factor & Good & Bad \\
\hline 1 & C.O.B & $\begin{array}{l}\begin{array}{l}\text { Negative(if milk not } \\
\text { clots) }\end{array} \\
\end{array}$ & Positive \\
\hline 2 & ACIDITY & 0.108 to 0.135 & $>0.153$ \\
\hline 3 & $\begin{array}{ll}\text { HEAT } & \text { STA- } \\
\text { BILITY } & \end{array}$ & 0.5 to 0.6 & Below 0.4 \\
\hline 4 & M.B.R.T & $\begin{array}{l}\text { Above 2:00 to } 3: 00 \mathrm{hrs} \\
\text { good, } \\
\text { Above 3:00 very good }\end{array}$ & $\begin{array}{l}\text { Below } 1: 30 \\
1: 30 \text { to } 2: 00 \\
\text { satisfactory }\end{array}$ \\
\hline 5 & PHOSPHATE & $\begin{array}{l}\text { If it indicates white col- } \\
\text { our }\end{array}$ & $\begin{array}{lr}\text { If it indicates } \\
\text { pale } \quad \text { yellow } \\
\text { colour }\end{array}$ \\
\hline 6 & ALCOHOL & $\begin{array}{l}\text { If milk changes to orange } \\
\text { colour by mixing of } 1: 1 \\
\text { ratio alcohol and milk } \\
\text { then milk is considered } \\
\text { as good quality milk }\end{array}$ & $\begin{array}{l}\text { If milk changes } \\
\text { to pink colour } \\
\text { by mixing of } \\
1: 1 \text { of milk and } \\
\text { alcohol then it } \\
\text { is bad }\end{array}$ \\
\hline 7 & FAT & \multicolumn{2}{|c|}{$\begin{array}{l}\text { It doesn't have good or bad, increase in fat } \\
\text { content increase the demand and price of } \\
\text { milk, but Fat values are min } 1.5 \text { for double } \\
\text { toned milk and } 8.5 \text { for gold (the highest cost } \\
\text { milk ) }\end{array}$} \\
\hline 8 & CLR & $\begin{array}{l}\text { If values are greater than } \\
28 \text { then milk is consid- } \\
\text { ered as good due to pres- } \\
\text { ence of low water level }\end{array}$ & $\begin{array}{l}\text { If values come } \\
\text { below } 26 \text { then } \\
\text { the milk is } \\
\text { considered as } \\
\text { bad because of } \\
\text { high water level }\end{array}$ \\
\hline
\end{tabular}

Milk distribution process is shown in fig 1.

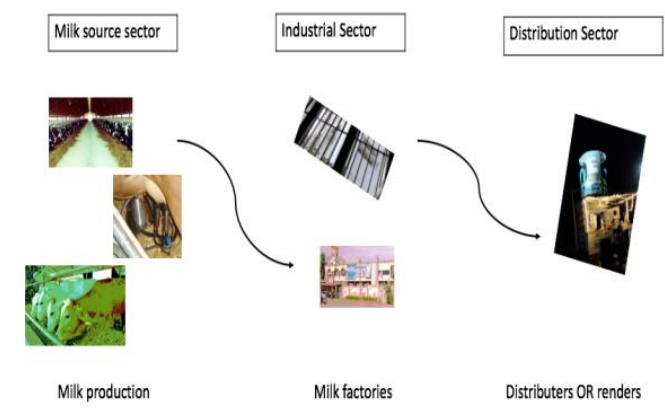

Fig. 1: Milk process

Here the process of collecting milk to distribution of milk is shown in pictorial form.

\section{About technology}

In today's world everything is upgrading rapidly, and our goal is making it simple and easy with Internet of Things (IoT). There are many IoT related technologies that we see in our day to day life. IoT means using new technological machineries that are interconnected to get information. In the quality testing of milk, we also use IoT devices like milk Oscan, MilkoScreen, EMT (Electronic Mikotest). These are the machineries used to test the milk quality and they are independent of each other and we use them for their respective analyses.For Example, we can use MilkoScreen to test Fat and SNF as it gives three parameters called Fat, SNF and Protein based on FTIR [8] technology and screening of any adulteration. It's 9compact and simple to use for mobility. We mostly use it when we want to test the milk on go or milk farms as it's a mobile device for calculation of Fat, SNF and Protein.And the second machine is EMT (Electronic Mikotest) which gives Fat and SNF. It's not that simple to carry and use like a mobile device, but we use this to test the milk on arrival at diary. After getting information about Fat and SNF we can conclude the milk quality. It means if Fat and SNF are not up to the mark then we use that milk for some other purpose like Milk powder or some other milk products. If those values are up to mark, then we take that milk to test in detail for calculation of Quality. For quality checking the machineries are getting upgraded day by day. Now the machinery used for calculation of milk is MilkoScan. It's is a device which is useful to get 15 parameters of milk (Fat, Protein, Lactose, Total Solids, SNF (Solids Not Fat), FPO, Total Acidity, Density, FFA, Citric acid, Casein, Urea, Glucose and Glactose). In this we are concentrating mostly on 8 factors like COB (Clotting On Boiling), Acidity, Heat Stability, MBRT (Methylene Blue Reduction Test), Phosphate, Alcohol, FAT, CLR, SNF which are enough to calculate quality of milk.

We are using Artificial Neural Network (ANN) for analysis of milk quality, because it runs on the inputs taken as testing and training of data and gives result to given input data. We give multiple samples of data to ANN for testing and training purpose then whenever we get a sample we test that sample quality using ANN. Generally, the MilkoScan works on the principle of FTIR (Fourier Transform Infrared Technology) and gives the output as a single $2 \times 16$ table (header and values, covering 15 factors).

\subsection{FTIR (Fourier transform infrared technology)}

This technology is used to collect high spectral resolution data simultaneously over solids, liquids or gas in a wide range. This technique is used to shine a monochromatic light as a sample and measures amount of light absorbed and it is repeated for each wavelength present. It generates a broadband light source which obtains full spectrum of wavelengths to be measured. All the system and calculations are depending on the wavelength generated by it. So, each wave is formed by the beam coming out of the interferometer. Computer takes all these wavelengths and uses a "Fourier transform algorithm" (decomposes the function of time into frequency) to give an output like the samples we get in computer. The raw data can also be called as "interferogram". This is converted to a spectrum by "Fourier transformation". This is sent to beam to store the data in a digital form as a series. This approach (interpolation [10]) gives accurate results in conversion of analog to digital. The instrument, spectrophotometer [11] is useful for calculation of wavelengths, for each sample it takes 30 sec time, within which it analyses and gives the output. The output we get from Milk Oscan is stored in an application user-interface which comes bundled with the machinery for simple and easy calculation. The samples we've collected are above 500 in a ".csv" format for testing and training purpose, and we calculate the quality and frame it on the standards provided in introduction.

\section{Numerical example}

For a calculation process we have taken machinery results and compared them with manual calculations. In our work, we have included both ways of obtaining the results. One way is to use IoT devices and another is to manually carry out the process which requires skilled personnel (technical persons). Machinery calculations utilize IoT technology, which is very simple and quick process. The machineries we use to get values are Milkoscan, Silkscreen, and ElectronicMilkoTest. With these we will get the needed factor values available in the milk like Fat, Protein, Lactose, Total Solids, SNF (Solids Not Fat), FPO, Total Acidity, Density, FFA, Citric Acid, Casein, Urea, Glucose and Glactose. If we want to know milk quality, we need some main factors like COB (clotting on boiling), Acidity, Heat Stability, MBRT (methylene blue reduction test), Phosphate, Alcohol, FAT, CLR, SNF. These values can be collected from the machinery and as well as with manual calculations. With the help of Machinery process a sample takes $30 \mathrm{sec}$ to give our required factors present in the milk. MilkoScan gives 15 parameters, MilkoScreen gives 3 parameters, EMT gives Fat value and SNF value. Manual process 
involves testing the factors like $\mathrm{COB}$ (clotting on boiling), Acidity, Heat Stability, MBRT (methylene blue reduction test), Phosphate, Alcohol, FAT, CLR, SNF by different processes with different materials.

\subsection{COB (Clotting on boiling)}

Here we just take some sample and boil it. If milk gets coagulated then we consider it as damage, else we do further processes. Few samples of the milk are boiled for around 5-6 minutes to check for coagulation.

\subsection{Acidity}

We do alcohol test of milk for knowing the acid levels. For better quality, the acidity values should be between 0.108 to 0.153 . Normally we get 0.135 when raw milk arrives at the factory. $0.1 \mathrm{~N}$ $\mathrm{NaOH}, 3-5$ drops of phenolphthalein, $10 \mathrm{ml}$ milk $(9.2$ grams by ISO standard) are mixed to sterilize the milk, then a burette is used to take the readings.

Value=burette reading $* 0.09$ (standard value).

Example: 1.5 (burette reading) $* 0.09$ (standard value).

\subsection{Heat stability}

First $10 \mathrm{ml}$ of milk is taken and HCL with normality $0.1 \mathrm{~N}$ is added to it and stirred. In $10 \mathrm{ml}$ of milk, $0.5 \mathrm{ml}$ of HCL (in $1 \mathrm{ml}$ pipette) is added and shaken to mix it well. Then it is boiled at $100^{\circ} \mathbf{C}$ for 5- 7 min. If milk gets solid then that milk is consider to be damaged.

\subsection{MBRT (Methylene blue reduction test)}

$1 \mathrm{ml} \mathrm{MBR} \mathrm{solution} \mathrm{(blue} \mathrm{colour),} 10 \mathrm{ml}$ milk are mixed and boiled at room temperature $\left(27^{\circ} \mathbf{C}-30^{\circ} \mathbf{C}\right)$ and we have to check in each $20 \mathrm{~min}$ to test that the blue colour is fully changed into white. If it takes more time to change then it means that milk is very good.

\subsection{Phosphate}

$5 \mathrm{ml}$ of Phosphate solution and $1 \mathrm{ml}$ of milk are mixed together. This mixture is in white colour, if that changes to pale yellow then that is considered as positive (damaged). If the colour does not get changed then that is considered as negative (good). The colour change is checked for $1 \mathrm{hr}$. long. If this test is not done properly then the milk will get damaged as soon as it goes out.

Phosphate solution $=500 \mathrm{ml}$ distilled water $+0.75 \mathrm{gm}$ sodium carbonate +0.25 sodium bi-carbonate.

\subsection{Alcohol test}

This test is done with 1: 1 (milk quantity == alcohol quantity). $75 \%$ of alcohol for Buffalo milk and $68 \%$ of alcohol for Cow milk.

\subsection{CLR (Correct lactometer reading)}

Here two terms come into picture, LR and CLR. LR (lactometer reading) means the reading done at any temperature and follows the convention form for temperature conversion. CLR (Correct Lactometer Reading) means the tests are done at exact temperature $\left(21^{\circ} \mathbf{C}\right)$ as of standards. If we test the process at $21^{\circ} \mathbf{C}$ then that is called as CLR otherwise, the test is called as LR test. Test runs at $21^{\circ} \mathbf{C}$, which if changes, for every $3^{\circ} \mathbf{C}$ we add 1 to the result if temperature increases by $3^{\circ} \mathbf{C}$. Otherwise we decrease by 1 if temperature decreases by $3^{\circ} \mathbf{C}$ to the standard $\left(21^{\circ} \mathbf{C}\right)$.

\subsection{SNF (Solids not fat)}

\section{$\mathrm{SNF}=((\mathrm{CLR} / 4)+0.21 * \mathrm{FAT}+0.36)$}

For calculation of remaining factors, we use ATM (Adulteration Mikotest).

\section{Experimental results}

As mentioned in the paper, neural net and random Forest algorithm in ANN is used for the analysis of milk quality. As we know that ANN going to give outputs based on the inputs, ANN takes some samples for testing and some samples for training. If we provide some inputs based on tested and trained data, it will give outputs according to our inputs. In this we concentrated on SNF value based on that we've calculated taste of milk as a final results. For this purpose, we've taken more than 500 samples to test and train in ANN and we designed an algorithm to get the expected output for our input.

\begin{tabular}{|c|c|c|c|c|c|c|c|c|c|}
\hline$C .0 . B$ & ACIDTYY & HEAT STABILITY & MBRT & PHOSPHATE & ALCOHOL & FAT & CLR & SNF & TASTE \\
\hline 1 & 0.135 & 0.5 & & 0 & 58 & 6.8 & 27 & & GOOD \\
\hline 1 & 0.135 & 0.5 & & 5 & 57 & 7.2 & 28.5 & & GOOD \\
\hline 1 & 0.144 & 0.4 & & 0 & 59 & 7.6 & 26.5 & & GOOD \\
\hline 1 & 0.153 & 0.5 & & 0 & 58 & 6.7 & 27 & & GOOD \\
\hline 0 & 0.144 & 0.5 & & 0 & 56 & 6.5 & 27 & & $B A D$ \\
\hline 1 & 0.135 & 0.5 & & 5 & 60 & 7 & 28 & & G000 \\
\hline 1 & 0.189 & 0.5 & & 0 & 58 & 7.3 & 29.1 & & $B A D$ \\
\hline 1 & 0.135 & 0.5 & & 5 & 59 & 8.2 & 28 & & G000 \\
\hline 1 & 0.144 & 0.5 & & 5 & 58 & 8.1 & 27 & & GOOD \\
\hline 1 & 0.153 & 0.5 & & 0 & 58 & 7.3 & 28.5 & & GOOD \\
\hline 1 & 0.135 & 0.5 & & 0 & 58 & 6.5 & 26.5 & & $B A D$ \\
\hline 0 & 0.153 & 0.4 & & 5 & 58 & 7.2 & 27 & & $B A D$ \\
\hline 1 & 0.156 & 0.5 & & 0 & 59 & 7 & 26 & & $B A D$ \\
\hline 1 & 0.144 & 0.5 & & 0 & 57 & 6.5 & 28 & & GOOD \\
\hline 1 & 0.126 & 0.5 & & 0 & 60 & 8 & 26 & & GOOD \\
\hline 1 & 0.135 & 0.5 & & 0 & 68 & 7.2 & 27 & & GOOD \\
\hline 1 & 0.153 & 0.1 & & 0 & 58 & 7.6 & 28 & & GOOD \\
\hline 1 & 0.144 & 0.5 & & 5 & 59 & 7.4 & 27.5 & & GOOD \\
\hline 1 & 0.135 & 0.5 & & 0 & 58 & 7.8 & 27 & & G00D \\
\hline
\end{tabular}

Here these are some sample values where we mixed all good and bad milk values with respect to the factors and in order to find it manually we also provided table based on the values where we can directly say by seeing table and these samples.

\section{Conclusion}

We discussed the factors affecting the quality of milk from data collected from IoT devices, and analysed through ANN. The results are quite impressive and the predictive capability of quality of milk through ANN is $97.3 \%$. The technology can be used for different applications in different aspects. In this work, after completion of analysis of milk quality through sensors and the manual calculations, both are found to be quite similar, hence it is proved that the technology used to analyse the quality of milk, which we used is good and way better to use as it's a simple, easy and very quick process.

\section{References}

[1] Sahin E, Baba1 MZ, Yves D \& Renaud V, "Ensuring supply chain safety through time temperature integrators", The International Journal of Logistics Management, Vol.18, No.1, (2007), pp. $102-124$

[2] Mangina E \& Vlachos IP, "The changing role of information technology in food and beverage logistics management: Beverage network optimization using intelligent agent technology", Journal of Food Engineering, Vol.70, No.3, (2005), pp.403-420.

[3] Yue J, Liu L, Li Z, Li D \& Fu Z, "Improved quality analytical models for aquatic products at the transportation in the cold chain", Mathematical and Computer Modelling, Vol.58, No.3-4, (2013), pp.474-479.

[4] Brown E, "Who Needs the Internet of Things?". Linux.com, (2016).

[5] Nordrum A, "Popular Internet of Things Forecast of 50 Billion Devices by 2020 Is Outdated", IEEE, (2016).

[6] L^ffler HU, "Control of mechanical properties by monitoring microstructure", Association of Iron and Steel Engineers, (2000).

[7] Warde J \& Knowles DM, "Use OT Neural Networks for Alloy Design", Department of Materials Science and Metallurgy, PembrokeStreet. Cambridge, (1999).

[8] Griffiths P \& de Hasseth JA, Fourier Transform Infrared Spectrometry (2nd ed.), Wiley-Blackwell, (2007). 
[9] Gomez AH, He Y \& Pereira AG, "Non-destructive measurement of acidity soluble solids and firmness of Satsuma mandarin using Vis/NIR-spectroscopy techniques", Journal of food engineering, Vol. 77, No.2, (2006), pp.313-319.

[10] Brault JW, "New Approach to high-precision Fourier transform spectrometer design", Applied Optics, Vol.35, No.16, (1996), pp. 2891-2896. 